\title{
MEMORANDUM TO MEMBERS
}

The Council and the Board of Trustees of the Society wish to remind the members that legacies to the Society are invited and deeply appreciated, whether the amount be large or small. Indeed, the greatest hope of the Society lies in a multiplicity of small bequests. No one wishing to assist the Society should hesitate because his gift may be small. Those who are not in a position to assist the Society in this way may wish to call the attention of others to this method of furthering the cause of mathematics.

The relative value of any gift, small or large, to the Society is believed to be inestimably greater than the relative value of a similar gift to a university or other organization of greater scope and diverse purposes. The funds of the Society go directly into the advancement of mathematical research, and a small increase in the Society's funds will be more promptly and effectively reflected in a corresponding increase in activity than would be likely through any other channel.

The Society naturally prefers bequests of money which may be used, without restrictions, for its general work. However, funds restricted to certain purposes set forth by the donor will also be helpful provided they are not restricted unduly. For example, funds for the support of any or all of the Society's publications would be most welcome. Any of the officers of the Society will be happy to consult with prospective donors on these matters.

It is the policy of the Society to recognize a donor by attaching his name, or any other name specified by him as a memorial, to the fund given by him or to the activities supported by the fund.

The following sample form of bequest shows the legal name of the Society.

"I give and bequeath to the American Mathematical Society

(a corporation organized under the laws of the District of

Columbia) the sum of - - - - - - - - dollars."

Gifts and bequests to the Society are deductible for income, gift, and estate tax purposes.

E. G. BEGLE, Secretary 